\title{
Epididimite ovina por Actinobacillus seminis no Estado de Pernambuco $^{1}$
}

\author{
Mauro José Gonçalves Bezerra², André de Souza Santos², Jefferson Ayrton Leite de \\ Oliveira $\mathrm{Cruz}^{2}$, Eugênio de Souza Kung ${ }^{2}$, Silvio Gomes de Sá ${ }^{2}$, Flavia Figueiraujo \\ Jabour ${ }^{3}$, Marilene de Farias Brito ${ }^{4}$ Rinaldo Aparecido Mota ${ }^{2}$
}

\begin{abstract}
Bezerra M.J.G., Santos A.S., Cruz J.A.L.O., Kung E.S., Sá S.G., Jabour F.F., Brito M.F. \& Mota R.A. 2012. [Sheep epididymitis by Actinobacillus seminis in the state of Pernambuco, Brazil.] Epididimite ovina por Actinobacillus seminis no Estado de Pernambuco. Pesquisa Veterinária Brasileira 32(5):369-373. Laboratório de Doenças Infectocontagiosas dos Animais Domésticos, Universidade Federal Rural de Pernambuco, Rua Dom Manoel de Medeiros s/n, Recife, PE 52171-900, Brazil. E-mail: rinaldo.mota@hotmail.com

This study reports the occurrence of sheep epididymitis and the isolation of Actinobacillus seminis in the state of Pernambuco, Brazil. An increase in volume of the testicles and epididymis, pain and increase in the local temperature at palpation, and bilateral testicular atrophy were clinically observed. After slaughter, the presence of purulent content in the epididymis was found. In microscopy of the testicles, coagulation necrosis and calcification of seminiferous tubules, thickening of the tunica albuginea, fibrosis, inflammatory infiltrate with predominance of lymphocytes between seminiferous tubules and incipient mineralization of tubules was observed. In the epididymis, intense proliferation of conjunctive tissue and fibrosis around the epididymal ducts was found. The diagnosis of epididymitis by Actinobacillus seminis was confirmed with association of the clinical findings, isolation and identification of the bacteria, as well as through histopathological exam.
\end{abstract}

INDEX TERMS: Epididymitis, Actinobacillus seminis, sheep.

RESUMO-- Relata-se a ocorrência de orquite e epididimite ovina associada ao isolamento de Actinobacillus seminis no Estado de Pernambuco. Clinicamente observou-se aumento de volume nos testículos e epidídimos, dor e aumento de temperatura local à palpação, e atrofia testicular bilateral. Após o abate observou-se a presença de conteúdo purulento no epidídimo. À microscopia dos testículos observou-se espessamento da túnica albugínea, necrose de coagulação e calcificação de túbulos seminíferos, infiltrado inflamatório com predominância de linfócitos entre túbulos seminíferos, além de mineralização incipiente de túbulos. No epidídimo observou-se intensa proliferação de tecido conjuntivo ao

\footnotetext{
${ }^{1}$ Recebido em 16 de novembro de 2011.

Aceito para publicação em 12 de dezembro de 2011.

${ }^{2}$ Universidade Federal Rural de Pernambuco (UFRPE), Rua Dom Manoel de Medeiros s/n, Dois Irmãos, Recife, PE 52171-900, Brasil.* Autor para correspondência: rinaldo.mota@hotmail.com

3 Docente de Patologia do Curso de Medicina Veterinária do Centro Universitário Cesmac, Rua Cônego Machado, 918 Maceió, AL 57051-160, Brasil.

${ }^{4}$ Departamento de Epidemiologia e Saúde Pública, Instituto de Veterinária, Universidade Federal Rural do Rio de Janeiro (UFRRJ), Seropédica, RJ 23890-000, Brasil.
}

redor dos ductos epididimários. 0 diagnóstico de orquite e epididimite por Actinobacillus seminis foi confirmado pela associação dos achados clínico-patológicos, isolamento e identificação da bactéria.

TERMOS DE INDEXAÇÃO: Epididimite, Actinobacillus seminis, ovinos.

\section{INTRODUÇÃO}

A região Nordeste do Brasil concentra aproximadamente nove milhões de ovinos (IBGE 2008). Contudo, a produtividade ainda é muito baixa e os problemas sanitários e nutricionais limitam o potencial de crescimento dessa atividade (Vieira et al. 1998, Simplício et al. 2001). Dentre os principais entraves para a cadeia produtiva ovina, destacam-se as doenças infecto-contagiosas como as principais responsáveis por elevadas perdas econômicas nos rebanhos (Pinheiro et al. 2000).

A epididimite ovina é uma patologia que causa prejuízos econômicos, principalmente por interferir na fertilidade dos machos infectados. Esses efeitos, em geral não são percebidos especialmente em criações extensivas devido à 
falta de informação dos produtores sobre essa doença (Gomes et al. 1991).

Actinobacillus seminis foi inicialmente isolada por Baynes \& Simmons (1960), na Austrália, no sêmen de ovinos com epididimite. Posteriormente, Livingston \& Hardy (1964) isolaram a bactéria nos Estados Unidos da América. Worthington \& Bosman (1968) identificaram a bactéria na África do Sul, Gumbrell \& Smith (1974) na Nova Zelândia, Hajtós et al. (1987) na Hungria, Robles et al. (1990) na Argentina, Heath et al. (1991) no Reino Unido, e Puente-Redondo et al. (2000) na Espanha.

No Brasil, existem apenas três relatos sobre o isolamento de Actinobacillus seminis. 0 primeiro foi realizado por Schreiner et al. (1992) em um ovino macho da raça Texel no Estado do Rio Grande do Sul. Gomes et al. (2001) isolaram a bactéria em cinco reprodutores com epididimite também no estado do Estado do Rio Grande do Sul. Finalmente, a bactéria foi relatada no Estado de São Paulo por Gregory et al. (2009) em um ovino da raça Dorper que apresentou orquite, epididimite unilateral e queda da fertilidade, além de atrofia testicular unilateral.

Considerando as perdas econômicas causadas por esta enfermidade relatada em diversos países e, sobretudo, devido à ausência de registros do isolamento dessa bactéria na região Nordeste do Brasil, objetivou-se com esse estudo relatar a ocorrência dessa bactéria associada à orquite e epididimite ovina no Estado de Pernambuco, Brasil.

\section{MATERIAL E MÉTODOS}

Neste estudo, 25 carneiros em idade reprodutiva foram submetidos ao exame clínico no matadouro de Gravatá, Estado de Pernambuco. Após o abate, os animais que apresentaram lesões macroscópicas especialmente nos testículos e epidídimos foram identificados e separados e realizada a coleta de amostras para exames histopatológicos e microbiológicos.

As amostras para exame bacteriológico foram colhidas com auxílio de suabes após a abertura dos epidídimos e testículos com auxílio de bisturi estéril. 0 pus dos abscessos foi refrigerado e encaminhado ao Laboratório de Doenças Infecto-contagiosas da Universidade Federal Rural de Pernambuco. Posteriormente, os suabes foram semeados na superfície de ágar sangue ovino e as placas foram mantidas em estufa bacteriológica a $37^{\circ} \mathrm{C}$ por 72 horas. Após esse tempo, as colônias suspeitas foram submetidas às provas morfológicas e bioquímicas de identificação (redução de nitrato, indol, motilidade, ureia, catalase, fermentação da glicose, sacarose e lactose) de acordo com Meyer \& Cameron (1956) e Hatjós et al. (1987).

Amostras de testículo e epidídimo foram fixadas em formalina a 10\%, desidratadas, diafanizadas e incluídas em parafina. Os blocos foram cortados em micrótomo a $5 \mu$ e as lâminas coradas pela Hematoxilina-Eosina (HE).

\section{RESULTADOS}

Na avaliação clínica (inspeção e palpação) foram observadas alterações dos testículos e epidídimos em três ovinos (3/25). Os Ovinos 14 e 18 apresentaram atrofia testicular bilateral, consistência firme à palpação, além de resistência ao corte. O Ovino 12 apresentou aumento de volume bilateral testicular, edema, consistência firme à palpação, temperatura aumentada e ausência de mobilidade dos tes- tículos no saco escrotal. Os epidídimos apresentaram aumento de volume em toda a sua extensão e edema. Ao corte observou-se presença de conteúdo purulento bilateral de coloração amarelada.

0 exame bacteriológico foi positivo apenas para a amostra do conteúdo purulento dos epidídimos do Ovino 12. A bactéria isolada apresentou características morfotintoriais e bioquímicas que permitiram identificá-la como Actinobacillus seminis.

Ao exame histopatológico do Ovino 12 foram observados no cordão espermático, necrose do epitélio do ducto deferente, fibrose da parede do ducto, debris celulares intraluminais, acentuada fibrose intersticial e leve infiltrado inflamatório predominantemente mononuclear no interstício e ao redor de vasos e do ducto. Na túnica albugínea havia necrose, infiltrado inflamatório piogranulomatoso e acentuada fibrose. 0 epidídimo apresentava

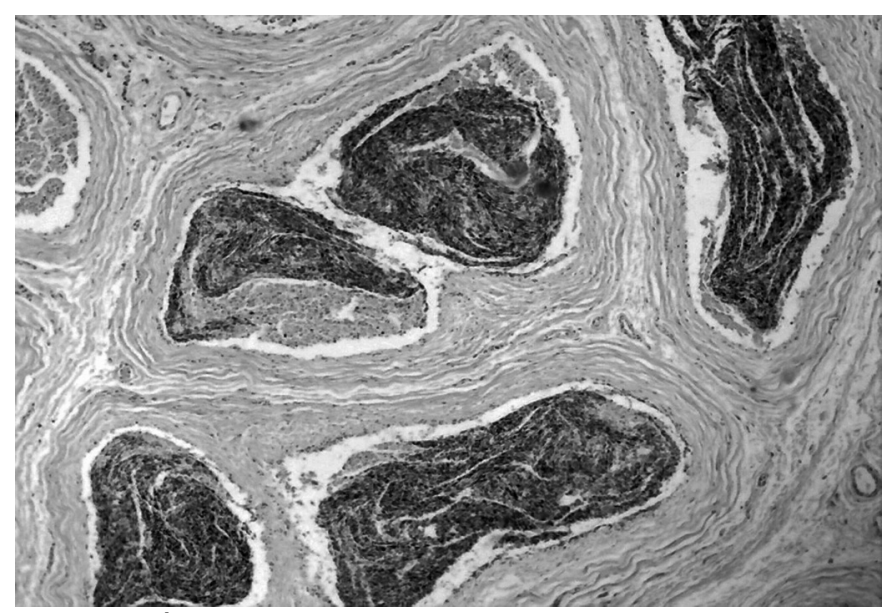

Fig.1. Epidídimo do Ovino 12 com intensa proliferação de tecido conjuntivo fibroso ao redor dos ductos epididimários, destruição do epitélio dos ductos, infiltração linfocitária leve e debris celulares em meio a espermatozoides necróticos e com mineralização incipiente. HE, obj.16x.

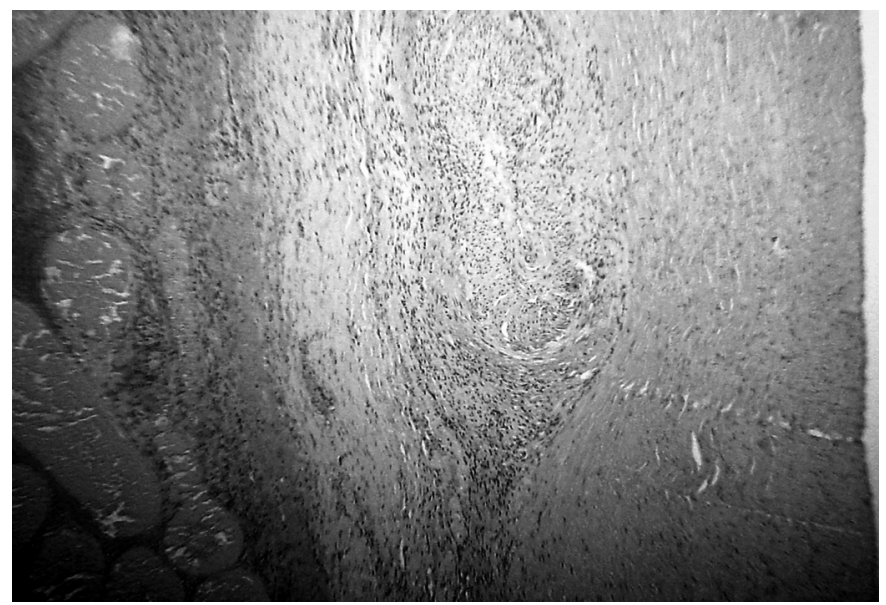

Fig.2. Espessamento da túnica albugínea do Ovino 14. À esquerda e ao centro proliferação de fibroblastos e presença de macrófagos carregados de pigmento amarelado, dispersos em meio à reação inflamatória granulomatosa; à direita, necrose de coagulação de túbulos seminíferos e infiltrado inflamatório mononuclear intersticial. HE, obj.4x. 


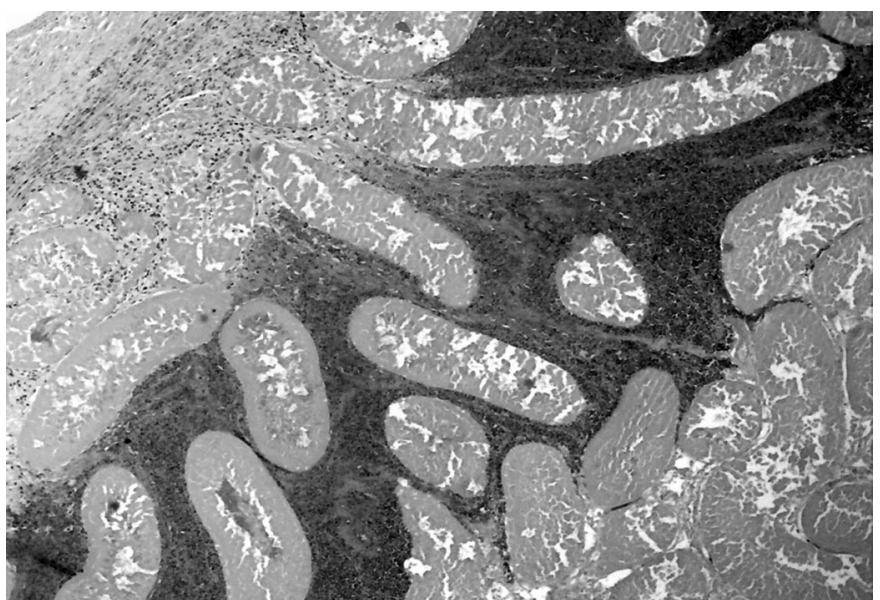

Fig.3. Testículo do Ovino 14. A túnica albugínea (canto superior esquerdo) está espessada e no testículo há necrose de coagulação massiva; nas áreas mais periféricas e próximas à túnica albugínea há uma faixa de infiltrado inflamatório predominantemente linfocitário e debris celulares entre os túbulos seminíferos. HE, obj.4x.

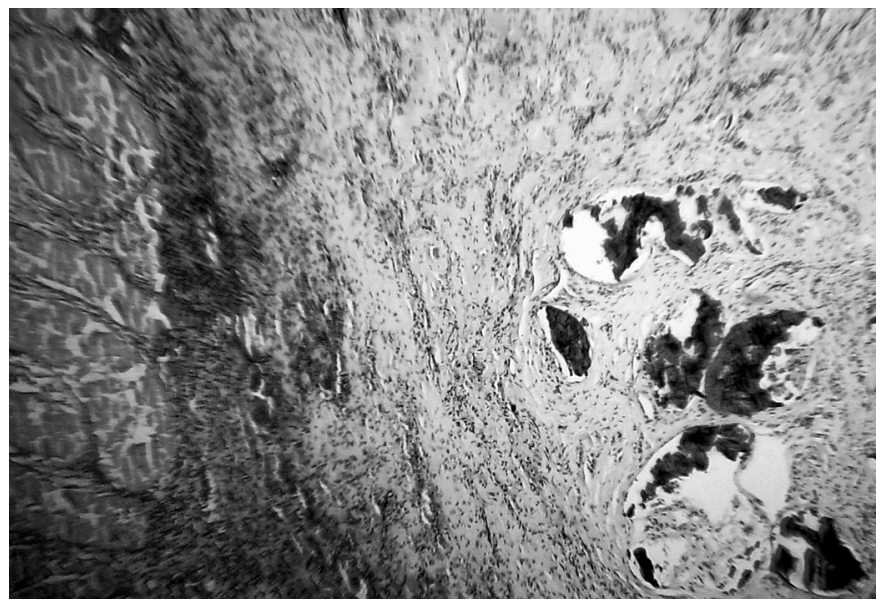

Fig.4. Testículo do Ovino 14 aderido ao epidídimo por reação inflamatória granulomatosa; nos ductos epididimários há placas de mineralização e fibrose intersticial. Nota-se que no testículo há necrose de coagulação e infiltração inflamatória intersticial. HE, obj.4x.

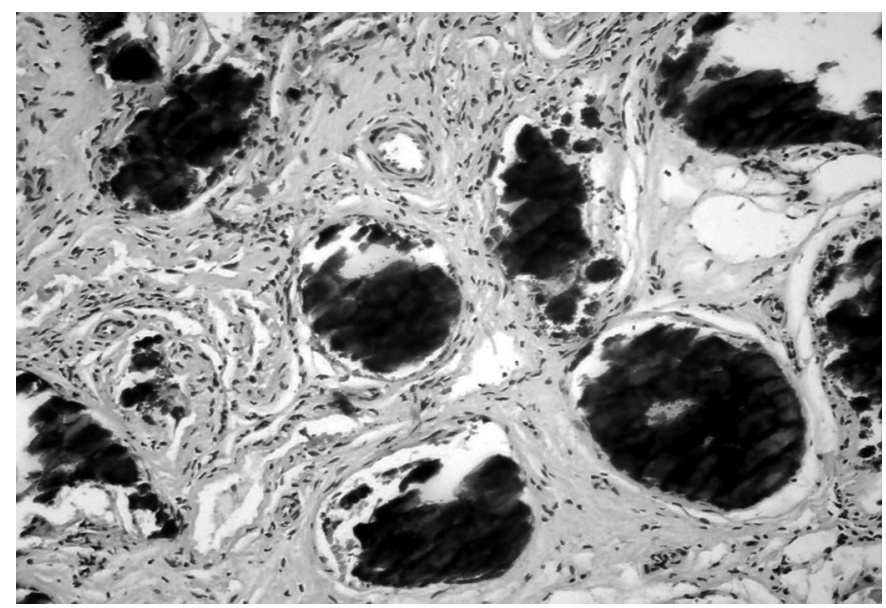

Fig.5. Epidídimo do Ovino 18 com intensa proliferação de tecido conjuntivo fibroso ao redor dos ductos e extensa mineralização intraductal. HE, obj.16x. intensa proliferação de tecido conjuntivo fibroso ao redor dos ductos epididimários, destruição do epitélio dos ductos, infiltração linfocitária leve e debris celulares em meio à espermatozoides necróticos e com mineralização incipiente (Fig.1). 0 testículo apresentava evidente diminuição das células da linhagem espermática.

No Ovino 14 a túnica albugínea apresentava densa proliferação de tecido conjuntivo fibroso e numerosos macrófagos carregados de pigmento amarelado ouro em meio à fibrose. No testículo havia, nas áreas mais periféricas e próximas à túnica albugínea, infiltrado inflamatório predominantemente linfocitário e debris celulares entre os túbulos seminíferos que apresentavam necrose de coagulação massiva. No centro de alguns túbulos necróticos podia-se ver material eosinofílico em meio a imagens filamentosas (espermatozoides necróticos) semelhantes a depósitos de imunoglobulinas, e mineralização incipiente em alguns túbulos seminíferos (Fig.2-3). 0 epidídimo desse ovino apresentava intensa proliferação de tecido conjuntivo fibroso ao redor dos ductos e extensa mineralização intraductal (Fig.4); em outra área havia além da fibrose intersticial, ausência do epitélio, redução e até ausência de espermatozoides nos ductos epididimários e numerosos grânulos de mineralização no conteúdo.

No Ovino 18 havia acentuado espessamento da túnica albugínea, caracterizado por extensa proliferação de fibroblastos, e dispersos nas áreas de fibrose, viam-se numerosos macrófagos carregados de pigmento amarelo ouro. 0 epidídimo encontrava-se aderido ao testículo por reação inflamatória granulomatosa, e em seus ductos havia grandes placas de mineralização e fibrose intersticial (Fig.5). Em outra área, além da fibrose intersticial, havia ausência do epitélio dos ductos, marcada diminuição da densidade espermática, debris celulares e grânulos de mineralização intraluminal. No testículo havia necrose de coagulação massiva de túbulos seminíferos. Nas áreas mais periféricas do testículo, o interstício apresentava uma extensa faixa basofílica de reação inflamatória intersticial (debris celulares/mineralização incipente).

\section{DISCUSSÃO}

Clinicamente, a doença caracteriza-se por alterações inflamatórias crônicas que envolvem o epidídimo e o testículo. Observa-se, à inspeção e à palpação, aumento de volume, dor e aumento de temperatura local, atrofia testicular uni ou bilateral, abscessos e grânulos de mineralização em diferentes partes do epidídimo, que podem ser uni ou bilaterais, além de grandes coleções purulentas no saco escrotal. Essas alterações foram observadas em três animais desse estudo com exceção do conteúdo purulento que foi observado apenas nos epidídimos do Ovino 12 e a bactéria Actinobacillus seminis foi isolada apenas nesse animal. Ainda podem ocorrer rupturas do escroto com descargas de conteúdo purulento, sinais sistêmicos em infecções agudas, principalmente, em carneiros jovens, que levam o animal à morte (Baynes 1960, Tonder 1973, Sponemberg et al. 1983, Gomes et al. 2001).

0 efeito na fertilidade do macho depende da intensidade da infecção e nos casos mais graves pode causar este- 
rilidade (Baynes 1960, Tonder 1973, 1979). As alterações clínicas estão associadas à baixa concentração, baixa motilidade e a não viabilidade espermática, além da presença de neutrófilos no sêmen. Essas alterações comprometem a taxa de fertilidade dos reprodutores e nas regiões onde a doença não foi diagnosticada anteriormente, os prejuízos econômicos podem ser ainda maiores.

Gomes et al. (1991) comentam que os efeitos da infecção por Actinobacillus seminis não são perceptíveis nem mensuráveis, especialmente em criações extensivas ou por produtores não alertados para a importância econômica da doença. Nesse caso, é importante incluir esse agente infeccioso como causa de epididimite em reprodutores ovinos na região estudada para diferenciar das lesões clínico-patológicas causadas por Brucella ovis nos rebanhos. Outras bactérias como Corynebacterium pseudotuberculosis, Histophylus somni e Pasteurella haemolytica, além do Staphylococcus spp. e Streptococcus spp. também podem estar associados à epididimite e infertilidade em ovinos (Jansen 1980, Cardenas \& Maki 1986). É importante considerar que $A$. seminis e Histophilus somni são habitantes naturais e oportunistas da cavidade prepucial de ovinos após 12 semanas de idade e possivelmente a epididimite se desenvolve pela rota ascendente que a bactéria pode assumir em condições de estresse nutricional, de transporte e trocas hormonais durante a maturação sexual (Jansen 1983, Foster \& Lads 2007).

As lesões macroscópicas caracterizam-se por aumento de volume da cauda do epidídimo, de um ou de ambos os testículos, em até mais de cinco vezes, mas a cabeça e o corpo também podem estar afetados, espessamento da túnica albugínea, epididimite, orquite, atrofia e diminuição na consistência testicular, além de abscessos na cauda do epidídimo, no testículo e no saco escrotal; exsudato purulento, cremoso ou granular, branco acinzentado, ou material calcificado pode ser encontrado unilateral ou bilateralmente (West 2004, Foster \& Lads 2007, Moustacas et al. 2009). Ainda podem ser encontrado aumento dos linfonodos inguinais e ilíacos internos, bem como da glândula bulbouretral. A maioria dessas lesões estavam presentes no Ovino 12 e devem ser consideradas no diagnóstico das epididimites infecciosas agudas, embora a sua etiologia só possa ser definida por meio do exame bacteriológico ou técnicas moleculares, pois outras bactérias podem causar lesões semelhantes. Nos Ovinos 14 e 18, embora o resultado bacteriológico tenha sido negativo, a atrofia e a fibrose e a mineralização testicular e epididimal bilateral é compatível com o quadro crônico da enfermidade, o que dificulta o isolamento bacteriano, desta e de outras bactérias.

De acordo com Baynes (1960), Tonder (1973), Puente-Redondo et al. (2000), Gomes et al. (2001) e West (2004) na epididimite subaguda a crônica, as lesões histológicas causadas pelo $A$. seminis geralmente consistem de edema e fibrose intersticial do epidídimo, oclusão dos ductos epididimários com ausência de espermatozoides, reação inflamatória predominantemente linfoplasmocitária intersticial multifocal no testículo, mineralização de alguns túbulos seminíferos, necrose e inflamação piogranulomatosa no epidídimo e testículo, redução ou ausência de espermatozoides nos túbulos seminíferos, áreas de vacuolização do epitélio com pouca evidência de espermatogênese, além de atrofia tubular com retenção espermática e formação de granulomas. Na infecção aguda, as lesões descritas por West (2004) correspondem a necrose, descamação do epitélio e alterações císticas dos túbulos da parte afetada do epidídimo, infiltração por neutrófilos, e alguns macrófagos e linfócitos, e degeneração e necrose de neutrófilos e espermatozoides. Os achados microscópicos observados nos animais desse estudo estão de acordo com os citados na literatura, com algumas pequenas variações que a nosso ver, provavelmente se relacionam com as diferentes fases da doença, e também podem ser encontradas em outras orquites e epididimites causadas por Brucella ovis, Actinobacillus seminis, Histophilus somni, Haemophillus spp., Arcanobacterium (Corynebacterium) pyogenes, Corynebacterium pseudotuberculosis, Mannheimia haemolytica e Escherichia coli. Enquanto Brucella ovis causa epididimite em carneiros mais maduros os outros microorganismos pleomórficos gram-negativos causam lesões similares no epidídimo de carneiros virgens, o que sugere tratar-se de uma entidade que depende da experiência sexual do animal (Foster \& Lads 2007).

0 diagnóstico da doença deve ser feito considerando-se os achados clínicos, anátomo e histopatológicos, e principalmente no isolamento do agente bacteriano (Sponemberg et al. 1983). 0 exame sorológico não tem demonstrado resultados satisfatórios (Baynes 1960, Tonder 1973, 1979, Hajtós et al. 1987, Gomes et al. 2001). Saunders et al. (2007) também indicaram a PCR como um método bastante eficiente para o diagnóstico de Actinobacillus seminis.

Considerando os achados desse trabalho fica evidente a necessidade de realizar estudos mais abrangentes nesta e em outras regiões do país para conhecer o real envolvimento dessa bactéria na epididimite ovina, além dos prejuízos econômicos causados por esta doença.

\section{CONCLUSÃO}

Registra-se a ocorrência de epididimite crônica ovina e orquite necrosante por Actinobacillus seminis no Estado de Pernambuco, o que indica a necessidade de incluir esse agente infeccioso como causa de orquite e epididimite em reprodutores ovinos na região estudada.

\section{REFERÊNCIAS}

Baynes I.D. \& Simmons G.C. 1960. Ovine epididymitis caused by Actinobacillus seminis n.sp. Aust. Vet. J. 36:454-459.

Cardenas A.L. \& Maki L.R. 1986. Detection of antibody in rams with contagious epididymitis, using the enzyme-linked immunosobent assay. Am. J. Vet. Res. 47:738-739.

Foster R.A. \& Lads P.W. 2007. Male genital system, p.590-591. In: Jubb K.V.F., Kennedy P.C. \& Palmer N. (Eds), Phatology of Domestic Animals, $5^{\text {th }}$ ed. Vol. 3, Saunders Elsevier, Totonto.

Gomes M.J.P. 1991. Isolamento e identificação de Chlamydia psittaci de reprodutores bovinos com adenite vesicular, no Estado do Rio Grande do Sul. Dissertação de Mestrado em Microbiologia Veterinária, Universidade Federal Rural do Rio de Janeiro, Seropédica. RJ. 95p.

Gomes M.J.P., Driemeier D., Bonetti A.L., Eidt M. \& Azambuja D.R. 2001. Epididimite ovina: isolamento de Actinobacillus seminis, no Rio Grande do Sul, Brasil. Arq. Fac. Vet. UFRGS 29:55-58. 
Gregory L., Rizzo H.H., Meira Junior E.B.S., Lins G.J.V., Lins G.P.V. \& Pinheiro E.S. 2009 Relato do primeiro caso de orquite e epididimite unilateral ovina causada por Actinobacillus seminis no estado de São Paulo, Brasil. Revta Bras. Reprod. Anim. 33(2):105-107.

Gumbrell R.C. \& Smith J.M.B. 1974. Deoxyribonucleic acid base composition of ovine actinobacilli. J. General Microbiol. 84:399-402.

Hajtós I., Fodor L., Glávits R. \& Varga J. 1987. Isolation and characterization of Actinobacillus seminis strains from ovine semen samples and epididymitis. J. Vet. Med., B 34:138-147.

Heath P.J., Davies I.H., Morgan J.H. \& Aitken I.A. 1991. Isolation of Actinobacillus seminis from rams in United Kingdom. Vet. Rec. 129:304-307.

IBGE 2008. Produção da pecuária municipal, Brasil. Instituto Brasileiro de Geografia e Estatística, Rio de Janeiro, 35:1-62.

Jansen B.C. 1980. The etiology of rams epididymitis. Onderstepoort J. Vet. Res. 47:101-107.

Jansen B.C. 1983. The epidemiology of bacterial infection of the genitalia in rams. Onderstepoort J. Vet. Res. 50:275-282.

Livingston C.W. \& Hardy W.T. 1964. Isolation of Actinobacillus seminis from ovine epididymitis. Am. J. Vet. Res. 25:660-663.

Meyer M.E. \& Cameron H.S. 1956. Studies on the etiological agent of epididymitis in rams. Am. J. Vet. Res. 17:495-497.

Moustacas V.S., Carvalho Junior C.A., Costa E.A., Silva T.M.A., Xavier M.N., Paniago J.D.G., França S.A., Silva A.P.C., Miranda F.G. \& Santos R.L. 2009. Lesões macroscópicas de trato reprodutivo de ovinos experimentalmente infectados por Actinobacillus seminis. Anais 14을 Encontro Nacional de Patologia Veterinária, ABPV, Águas de Lindoia, SP. (Resumo)

Pinheiro R.R., Gouveia A.M.G., Alves F.S.F. \& Haddad J.P.A. 2000. Aspectos epidemiológicos da caprinocultura cearense. Arq. Bras. Med. Vet. Zootec. 52(5):534-543.

Puente-Redondo V.A., Garcia Del Blanco N., Pérez-Martínez C., Gonzales-Rodriguez M.C., Rodrigues-Ferri E.F. \& Gutiérrez-Martin C.B. 2000. Iso- lation of Actinobacillus seminis from the genital tract of rams in Spain. J. Comp. Pathol. 122:217-222.

Robles C.A., Urcullu J.A., Uzal F.A. \& Merio R. 1990. Primer diagnostico em Patagonia de orchideoepididimitis em carneros por bacilos pleomorficos Gram negativos. Vet. Argent. 7:453-455.

Saunders V.F., Reddacliff L.A., Berg T. \& Hornitzky M. 2007. Multiplex PCR for the detection of Brucella ovis, Actinobacillus seminis and Histophilus somni in ram semen. Aust. Vet. J. 85:72-77.

Schreiner E., Gomes M.J.P., Cardoso M.I., Fernandes J.C.T., Hope L.P., Laitano J.L.L. \& Fernandes R.E. 1992. Epididimite ovina: Isolamento de Actinobacillus seminis em Central de Inseminação Artificial no Rio Grande do Sul. XI Congresso Estadual de Medicina Veterinária, Gramado, RS, p.96. (Resumo)

Simplício A.A., Salles H.O., Santos D.O. \& Azevedo H.C. 2001. Manejo reprodutivo de caprinos e ovinos de corte em regiões tropicais. Documentos 35, Embrapa Caprinos, Sobral. 47p.

Sponenberg D.P., Carter M.E., Carter G.R., Cordes D.O., Stevens S.E. \& Veit H.P. 1983. Suppurative epididymitis in a ram infected with Actinobacillus seminis. J. Am. Vet. Med. Assoc. 182:990-991.

Tonder E.M.V. 1973. Infection of rams with Actinobacillus seminis. J. South African Vet. Med. Assoc. 44:235-240.

Tonder E.M.V. 1979. Actinobacillus seminis infection in sheep in the republic of South Africa. Identification of the problem. J. Vet. Res. 46:129-133.

Vieira L.S., Cavalcante A.C.R. \& Ximennes L.F. 1998. Epidemiologia e controle das principais parasitoses de caprinos nas regiões semi-áridas do Nordeste. Embrapa-CNPC, Sobral. 50p.

West D.M. 2004. Gram-negative pleomorphic infections: Actinobacillus seminis, Histophilus ovis and Haemophilus sommi, p.1655-1660. In: Coetzer J.A.W. \& Tustin R.C. (Eds), Infectious Diseases of Livestock. Vol.3. $2^{\text {nd }}$ ed. Oxford.

Worthington R.W. \& Bosman P.P. 1968. Isolation of Actinobacillus seminis in South Africa. J. South Afr. Vet. Med. Assoc. 39:81-85. 